\title{
The Research Progress and Trend of Guilt
}

\author{
Gengdan $\mathrm{Hu}$ \\ Department of Psychology \\ Tongji University \\ Shanghai, China 200092
}

\author{
Dan Wang \\ Department of Physical Education \\ Tongji University \\ Shanghai, China 200092
}

\begin{abstract}
Guilt, as one kind of negative emotional experience which is produced after individual violates moral criterion or hurts others, plays a crucial role in interpersonal communication and social moral criterion. Recent years, with the development of functional neural imaging, the research of guilt has been become hot issue in academic circles. On the basis of summaries of previous definitions and classifications of guilt, this essay analyzes similarities and differences of guilt and shame elaborately and raises reasonable explanations which discuss characters, merit rating and ranges of guilt research paradigms. It elaborates main current situation and problems of neural mechanisms research of guilt roundly and makes four expectations of guilt research trends.
\end{abstract}

Keywords-guilt; shame; compensation; neural mechanism; experimental paradigm

\section{INTRODUCTION}

Emotion is a state of being constantly aroused and experienced by individual and social emotion is produced in social communication, including guilt, hate, jealousy, gratitude, fear and so on. Social emotion, as a bond between individual life and social behavior, is of great importance. As a subcategory of emotion, social emotion could be divided into positive social emotion (gratitude, joviality and so on) and negative social emotion (guilt, fear and so on) according to valence.

Guilt means one kind of negative experience when individuals hurt others or violate personal moral principle. Guilt could be divided into condition awareness and cognitive processing of evaluation, emotional processing of negative experience producing and experience. Guilt, as one kind of utterly complex and social moral emotion which is tightly related to empathy ability, plays an important role in social actions and process of decision.

As the same of other self-awareness emotion, the complex guilt has two sides. On one hand, as one kind of negative emotional experience, guilt results in people punishing themselves due to their mistakes and feeling misery which may cause psychopathy. The existing researches suggest that guilt is related to obsessive compulsive disorder (Shafran, Watkins, \& Charman, 1996), depressive disorder (Tangney, 1991), antisocial personality (Pardin, Lochman, \& Frick, 2003); on another hand, guilt plays a positive role. From the perspective of sociology, guilt promotes positive relationship of people. It is regarded as the main cause of triggering prosocial behavior of adapting to society and cultural regulation (Carnı', Petrocchi, Del Miglio, Mancini, \& Couyoumdjian, 2013). Since it was studied, academic circles, however, has keep having a dispute over it due to the complexity of processing and effect. The main content of it is the distinction of specific process of guilt and other emotion such as shame, the principle of behavioristics and neural mechanism. The systematical analysis and summary of guilt researches condition and development could not only contribute to solve mentioned dispute but also deepen understanding of guilt which could make an accurate decision in daily interpersonal interaction.

\section{The ClassificAtion AND PROCESS OF GuILT}

Guilt would contribute to rendering ones comply with social rules spontaneously protecting others' rights. Some other researchers assume that people would feel guilt when they realize that they offend others or treat others unfairly. This kind of guilt driven by interpersonal empathy is called interpersonal guilt. It is based on moral empathy prompting ones to help others and leading to altruism playing an important role in maintaining the relationship between individuals and others. Researches of guilt function in this field have been verified.

When people violate moral principle and laws and regulations, they would raise the expectations of selfpunishment triggering guilt emotion whether the results would harm people. This kind of contradiction and conflict is called inner-drive guilt. In this regard, guilt could people obey social rules spontaneously in order that protect others' right. Otherwise, some researchers suppose that people would feel guilty when they are aware of offending others, treating others unfairly, or see others are more unfortunate than themselves. This guilt is driven by interpersonal empathy is called interpersonal guilt. The interpersonal empathy plays a crucial role in maintaining relationship between individual and others because it is based on moral empathy increasing the motivation of help others and triggering altruistic behaviors. Researches in this field have been proved in some guilt emotion functioning experiments (Baumeister, Stillwell, \& Heatherton, 1994; De Hooge, Zeelenberg, \& Breugelmans, 2007).

Furthermore, according to the length of guilt period, it could be divided into trait guilt and status guilt. Trait guilt means long-term stable character related to guilt and status guilt means instantaneously emotional experience triggered 
by special circumstance (Tilghman-Osborne, Cole, \& Felton, 2010).

Although, guilt is classified distinctly according to different trigger conditions, it is universally acknowledged that the psychological process of guilt could be divided into following aspects:

- Result-assessment. It means individual would primarily realize that matters bring out bad results or someone would be hurt after matters' occurrences.

- Self-awareness. Individuals realize that matters are related to themselves when they retrospect the process of matter carefully.

- Norm violation. Individuals realize they violate some norms, moral code or individual code.

- Responsibility assessment. Individuals would attribute the responsibility of matters' result to themselves and have a self-accusation.

- Self-assessment. Individuals would judge their selfimage and self-identity. Generally, they would judge themselves disparagingly. Someone, however, thinks that guilt is not related to self-image or self-identity.

- Behavior-attribution. It is divided into outer attribution and inner attribution. If individuals are inclined to inner attribution, they would think bad consequences result from what they do or not. If they tend to outer attribution, they would have less guilt.

- Compensation tendency. Individuals are apt to take some compensation behaviors in order to alleviate guilt.

Although in recent years, the researches on guilt emotion has been developed in nerves fields, it still remains guiding significance that explains the psychological process of guilt through praxeology.

\section{ThE Distinction OF GUILT AND SHAME}

Although scholars generally agree that social emotion is a key to restraining immorality and anti-social behavior, it still remains big controversy about definition, identification and measurement index of guilt and shame (Smith, Webster, Parrott, \& Eyre, 2002; Tangney, 1996; Tangney \& Dearing, 2002; Wolf, Cohen, Panter, \& Insko, 2010). It has remained divergence on research history that one kind of view suppose guilt and shame belong to one emotion so that one could replace another in researches. Tangney thinks whether guilt or shame is self-awareness emotion triggered by selfreflection and self-assessment which contributes to selfdiscipline (Tangney, 2003; Tracy \& Robins, 2004). This is the common ground of them. Many scholars, however, suppose that shame and guilt remain significant distinction. Those who support this view are divided into behavior and self-difference and public and private difference.

Behavior and self-difference suppose that guilt is one kind of emotional experience produced by self-negation, for example, I did something wrong today; Shame is negative emotion of self-negation such as I am evil (Lewis, 1971; Tangney, 1996; Tangney \& Dearing, 2002; Tracy \& Robins, 2004). According to this point, guilt is inner, unstable, specific ascription of individual behaviors. Shame is inner and comprehensive self-attribute, namely, absolute negation and disidentification of ego and individual. The Test of SelfConscious Affect-3 (TOSCA-3) is the most widely applied measure table which is used to estimate guilt and shame according to this hypothesis (Tangney, Dearing, Wagner, \& Gramzow, 2000). In this questionnaire, the trait of reflecting guilt is the regret, assessment of wrong behaviors (for instance, I think I make a mistake) and tendency of compensation (such as apology). The character of reflecting shame is negative self-assessment like I am a horrible person and tendency of withdrawal behavior like concealing. TOSCA-3 reveals that, compared with shame, guilt is one kind of more healthy emotional experience because guilt renders people realize their mistakes effectively and try to make an amendment and compensation.

From the perspective of anthropology, difference Difference of public and private school suppose that mistakes or failures which are not yet published such as private misdeed may trigger guilt while published unlawful act may cause shame (Ausubel, 1955; Combs, Campbell, Jackson, \& Smith, 2010; Smith, Webster, Parrott, \& Eyre, 2002). Based on this hypothesis, guilt is related to individual misbehaviors or personal experience of violating conscience to some extent. Shame is one kind of negative experience when an individual violation of law or moral is exposed DCQ is the scale based on this hypothesis (Johnson, Danko, Huang, Park, Johnson, \& Nagoshi, 1987). In this questionnaire, clauses of guilt would question interviewee the degree of negative emotional experience after making private mistakes such as embezzling office supplies and clauses of shame would question interviewee the degree of negative emotional experience after making public mistakes, for instance, making a fool of oneself after drunk.

In conclusion, school of action and self-difference and of public and private respectively reveal the essence, characters and triggering factors of guilt and shame from different aspects, they, however, both has their restrictions. For instance, school of action and self-difference only stresses the negation of self and does not involve in factors of ability or personality; when it defines shame, it only emphasizes the negation of self and personality and does not involve in selfaction. It is supposed whether guilt or shame, both of them include negative evaluation of self-action and personality but the degree is very different. Guilt tends to negate more selfaction and less personality while the condition of shame is adverse. Essentially, these two schools are not utterly opposite and related and supplied each other. These two theories are supposed to be integrated in order to make a more comprehensive and complete description. Therefore, the authors initially define these two concepts: Guilt is produced owing to individual negation of self-action or abilities in some aspects. The character of it is that all one's actions is private which is not published. Shame means individual would ascribe results of negative action to complete negation of the ego and personality after individual 
hurts others or violates moral principle. The trait of it is that shame is produced due to exposition of mistake actions and blame from the public.

The connotative meaning of guilt and shame in this definition are two different concepts which have obvious distinction and clear limit so that it could solve the dispute mentioned at the beginning.

\section{THE EXPERIMENTAL PARADIGM OF GUILT RESEARCH}

Early guilt researches mostly use scale to make the measurement. The measurement of scale realizes measured guilt emotion self-rating mainly according to the paradigm of scenario simulation. It sets some daily scenes which are displayed as brief behavior description, such as "I told a lie to my friend today) to make subjects have guilt experience. Scales made by this paradigm include Perceived Guilt Inventory (Otterbacher \& Munz, 1973), Guilt Inventory (Jones, Schratter, \& Kugler, 2000) and evaluation of adolescent guilt questionnaire invented by Japanese scholars (Arimitsu, 2002). Scales measurement, however, has its own limitation, for example, different understanding of materials would lead to deviation of measure results.

With the development of guilt researches, more and more people attempt to design paradigm to induce guilt emotion and carry on more comprehensive researches with scales. At present, common guilt experiment paradigm could be divided into three following class: individual reminiscence, text reading and scenario image and interpersonal interaction game (Wang, 2017).

Individual reminiscence or self-memory means reminding subjects of their individual experiences by specific ways to experience guilt. Wagner, N' Diaye, Ethofer and Vuilleumier (2011) once took this paradigm to research guilt emotion. They firstly got related guilt experiences with the form of questionnaire and show subjects' key words which are selected to trigger guilt emotion and induced them to recall and stimulate guilt experiences. Finally testers asked them to describe these experiences in detail.

Context reading and scenario image means subjects try to imagine specific scene and experience guilt through reading. Sophie, et al. (2010) displayed subjects' words triggering guilt, gratitude, embarrassment and so on. In the researches, friends of subjects are asked to use social concept words such as stinginess, selfishness to describe subjects' social action through written statement and require subjects describe their emotional experience accurately. Morey and other scholars (2012) compared the activation of the brain under two kinds of guilt-inducing conditions (self-guilt/guilt to others) and neutral conditions by this paradigm. They set two kinds of experimental procedure (each of them has 30 conditions). The example of the condition of self-guilt is I'm drunk driving and cash a tree after party. The instance of guilt to others is I hurt someone due to drunk driving and the neutral condition is I drove to home after having a drink on party. Subjects are asked to estimate the triggered guilt emotion in these mentioned conditions. Milla and Tesser (1988), in order to explore the trigger condition of guilt systematically, set 32 kinds of cheating condition and asked subjects to imagine the possibility under particular condition of cheating family members or employers and the degree of guilt based on specific context.

However, whether the paradigm of individual reminiscence or of context read and imagination is inevitably involved in processing words demonstrated on the screen which refers to the cognitive processing of brain. It would affect reliability of experimental results owing to subsequent emotional experience and modified language of subjects' true view of guilt degree which results in difficulties of distinguishing cognitive process and guilt emotional experience process. Recent years, the paradigm of interpersonal interaction game could amend the restrictions of mentioned two paradigms. The paradigm of interpersonal interaction game means that it studies guilt through multiplayer game. It sets punishment regulation that one side would be punished due to the action of other sides which could trigger guilt and make compensation. The merit of this paradigm is instantaneity and authenticity of emotional experience which could trigger guilt many times in one experiment.

In conclusion, interpersonal interaction game is supposed to be a better paradigm through summarizing paradigms of guilt researches. Some researchers have taken interpersonal interaction game paradigm to take brain imaging study (Koban, Corradi-Dell' Acqua, \& Vuilleumier, 2013; Wang, 2017), but this kind of research project is still at early exploration stage.

\section{THE NEURAL MEChANISM OF GUILT}

In the recent decade, the rapid development of neural imaging has boosted the exploration of guilt emotion neural mechanism, including electrosignal-based methods (EEG, ERP), hemodynamic-based methods (MEG, PET, fMRI, TMS) and so on. With PET, Shin, et al. (2000) discovered that, compared with neutral circumstance, rCBF would increase in limbic cortex forepart under guilt circumstance, including anterior cingulate cortex, bilateral anterior temporal poles, left prosencephalon to inferior frontal gyrus part.

Except PET and many other ways, more researches take fMRI to scan functional brain activities under guilt emotion. Morey and other scholars (2012) compared with activation condition of brain under guilt (self-guilt and guilt to others) triggering condition and neutral condition, through the paradigm of context reading and imagination, and they found that, compared with neutral condition, whether under the condition of self-guilt or guilt to others, it has more strong activation in internal and external prefrontal lobe, posterior cingulate cortex, precuneus and superior temporal sulcus. Related analysis has demonstrated the intensity of guilt is related to activation of dorsal medial prefrontal cortex (DMPFC), superior frontal gyrus, supramarginal gyrus and prefrontal gyrus. Takahashi and others (2004) analyzed guilt and shame with fMRI and results showed that guilt activate superior temporal sulcus (STS), medial frontal lobe (mPFC) and visual cortex; Compared with guilt, shame has high activate degrees in right temporal lateral, bilateral 
hippocampal and visual cortex. These mentioned researches have taken the paradigms of individual reminiscence, context reading and imagination which demonstrate that guilt related encephalic region is related to encephalic region of theory of mind (ToM) such as temporo-parietal junction and medial prefrontal cortex and self-awareness emotion related encephalic region such as insula.

Chang, Smith, Dufwenberg and Sanfey (2011) used interpersonal interaction game with results of magnetic resonance imaging (MRI) to find that the more strong selfinterest motivation of subjects are, the more active action of ventral striatum is, and when subjects have strong guilt, their insula, anterior cingulate cortex action are active. Moreover, related analysis show that there is a positive correlation between insula activation triggered by guilt and inner emotional experiences and their guilt characters of subjects. $\mathrm{Yu}, \mathrm{Hu}, \mathrm{Hu}$ and Zhou (2013) found that with the same paradigm of interpersonal interaction game, through fMRI scan, the compensation tendency of subjects under guilt emotion is much more intense and actions of bilateral insula and anterior cingulate cortex are also much more active. In regard to brain structure, ectocinerea of anterior cingulate cortex could predict compensation action. Mediation analysis additionally finds that some nucleus of anterior cingulate cortex and mesencephalon, such as periaqueductal gray (PAG), plays an important role in the cognitive process of guilt triggering experience and subsequent compensation action (Koban, Corradi-Dell' Acqua, \& Vuilleumier, 2013).

Through the summary of brain function related to guilt, it is apparent that neural mechanism research of social emotion has been a hot issue, but as far as guilt research concerned, the number of related neural mechanism material is still not enough. It demonstrates that there are some differences of brain regions related to guilt in different research reports. It could infer that, supposedly, what make distinct are differences of research paradigms, for example, there is an apparent difference of activation of brain region between the paradigm of context reading and imagination and of interpersonal interaction game. It is believed that with the development of social emotion research, the paradigm of guilt triggering would be simplified and accurate which could explore the neural mechanism of guilt.

\section{Guilt OF SPECIAL CROWd (TAKING SPORTSMAN FOR INSTANCE)}

This essay mainly uses document analysis to conclude that, in the process of referring to more than 70 documents, the majority of guilt study object is common people especially students. In fact, guilt, as important social emotion, is beneficial to interpersonal interaction due to spontaneous compensation and apology action, playing an indispensable role in all walks of life, especially some teamwork project like teamwork sportsmen (basketball, football and so on). Sportsmen, especially ranking sportsmen, have trained for long period and have a different growth and learning condition compared with common people. Due to the great intensity or length period of training and utterly simple interpersonal relationship, their long-term lifestyle is tedium. In their daily life and training, sense of group honor is cultivated to be strong which is apparent in sportsmen who play team sport. In some sport games or training like basketball or football, sportsmen would feel badly guilt on account of their own faults leading to teammates or team lost. This would cause in two results.

Firstly, if sportsmen feel guilt in the game, it would be very possible for them to make wrong decisions affecting results of games and resulting in failures. Many examples of domestic and foreign games have proved those who could keep their mood and tackle the game reasonably and make an appropriate decision would win the initiative if two teams are equally matched in physics and strategy. Relation of emotion and decision researches in sports field shows that, generally, positive emotion is beneficial to sportsmen decision making. It is effective in relevant fields like basketball (Arruda, Aoki, Freitas, Drago, Oliveira, Crewther, \& Moreira, 2014; Uphill, Groom, \& Jones, 2014), football (Yoon \& Yoon, 2014) and so on.

Secondly, if sportsmen feel guilt in daily training, they would either perform unstably and slackly or endeavour to train based on compensation emotion which could promote themselves. It could conclude from this point that, whether in daily training or game guilt emotion of sportsmen plays an important role. Therefore, lucubrating guilt (including trigger principle of sportsmen guilt, how to self-adjust or control guilt emotion) of sportsmen could prevent them from selfsatisfied and slack which render them keep mood stable. It could not only raise efficiency of daily training but also help sportsmen keeping stable in important tournament which is vital for improving their performance.

Based on the experimental group of 20 professional football athletes (9 level-1 athletes and 11 level-2 athletes) and the control group of 20 ordinary undergraduates, with interactive multiplayer game paradigm, Wang (2017) researched guilt of athlete and related neural activities. The results indicated as follows:

When other conditions were held the same, higher level athletes had a stronger sense of guilt, and would commit more compensation.

For athletes within the same level, if one's mistakes could cause harm to others, the athletes experienced a stronger sense of guilt than undergraduates did, indicating a stronger tendency for compensatory behavior.

Athletes' perception of guilt involved areas of the brain, including the dorsolateral prefrontal cortex, caudate nucleus and parietal lobe. Particularly for the parietal region, rank factors could influence the sense of guilt through the activities in that region.

The results of the comparison of guilt-related brain areas between the first and second level athletes were highly consistent with the trend of the difference between the results of the comparison between football athletes and ordinary undergraduates, with the former higher than the latter. This demonstrates from the perspective of neuroscience that athletes have a sense of guilt more intense than undergraduates, and there are significant differences 
regarding the degree of guilt senses among athletes of different levels.

\section{CONCLUSION}

This essay summarizes guilt and neuroscience researches that guilt as one kind of complex and universal social emotion has been caught academic attention increasingly, but the potential of researches' rage and depth is still to be exploited. This essay has discussed the classification of guilt systematically and has made an elaborate analysis of dispute related to guilt, for instance, whether guilt and shame are the same concept, making a comprehensive description of the distinction of guilt and shame. Additionally, it has summarized and discussed researches paradigms and neural mechanism of guilt. Based on the foundation of existing results, the author supposes that the future researches of guilt could be conducted in the following aspects.

Firstly, some necessary experimental paradigms of cranial nerve about guilt are supposed to be discussed and innovated further in order to find more brief and accurate paradigms stimulating guilt of subjects.

Secondly, the existing researches of neuroscience have neglected contact relationship of brain regions involved in processing to some extent and they could be conducted with correlation between nerve tracts of guilt and brain regions.

Thirdly, due to different influential factors of guilt (such as the degree of expectation of others, the severity degree of wrong action, ways of attribution and so on), the different degree of guilt and influence of subsequent compensation could be studied.

Fourthly, in regard to the important role of guilt in interpersonal interaction, the guilt of special group is supposed to be discussed furthermore.

\section{ACKNOWLEDGEMENT}

This work was supported by Key Project of School Sports Scientific Research in Shanghai (HJTY-2016-C02); Social Sciences Interdisciplinary Project of Tongji University (1430219042).

\section{REFERENCES}

[1] Arimitsu, K. Structure of guilt eliciting situations in Japanese adolescents, The Japanese Journal of Psychology, 2002, 73, 148-156.

[2] Arruda, A. F., Aoki, M. S., Freitas, C. G., Drago, G., Oliveira, R., Crewther, B. T., \& Moreira, A. Influence of competition playing venue on the hormonal responses, state anxiety and perception of effort in elite basketball athletes. Physiol Behav, 2014, 130, 1-5.

[3] Ausubel, D. P. Relationships between shame and guilt in the socializing process. Psychological Review, 1955, 62, 378-390.

[4] Baumeister, R. F., Stillwell, A. M., \& Heatherton, T. F. Guilt: An interpersonal approach. Psychol Bull, 1994, 115, 243-267.

[5] Carni, S., Petrocchi, N., Del Miglio, C., Mancini, F., \& Couyoumdjian, A. Intrapsychic and interpersonal guilt: a critical review of the recent literature. Cogn Process, 2013, 14, 333-46.

[6] Chang, L., Smith, A., Dufwenberg, M., \& Sanfey, A. Triangulating the neural, psychological, and economic bases of guilt aversion. Neuron, 2011, 70, 560-72.
[7] Combs, D. J. Y., Campbell, G., Jackson, M., \& Smith, R. H. Exploring the consequences of humiliating a moral transgressor. Basic and Applied Social Psychology, 2010, 32, 128-143.

[8] De Hooge, I. E., Zeelenberg, M., \& Breugelmans, S. M. Moral sentiments and cooperation: differential influences of shame and guilt Cogn Emot, 2007, 21, 1025-1042.

[9] Green, S., Ralph, M. A. L., Moll, J., Stamatakis, E. A., Grafman, J., $\&$ Zahn, R. Selective functional integration between anterior temporal and distinct fronto-mesolimbic regions during guilt and indignation. Neuroimage, 2010, 52, 1720-6.

[10] Johnson, R. C., Danko, G. P., Huang, Y. H., Park, J. Y., Johnson, S. B., \& Nagoshi, C. T. Guilt, shame and adjustment in three cultures. Personality and Individual Differences, 1987, 8, 357-364.

[11] Jones, W. H., Schratter, A. K., \& Kugler, K. The guilt inventory. Psychol Rep, 2000, 87, 1039-1042.

[12] Koban, L., Corradi-Dell' Acqua, C., Vuilleumier, P. Integration of error agency and representation of others' pain in the anterior insula. $\mathrm{J}$ Cogn Neurosci, 2013, 25, 258-272.

[13] Lewis, H. B. Shame and guilt in neurosis. New York: International Universities Press, 1971.

[14] Millar, K. U., \& Tesser, A. Deceptive behavior in social relationships: A consequence of violated expectations. J Psychol, 1988, 122, 263273.

[15] Morey, R. A., Mccarthy, G., Selgrade, E. S., Seth, S., Nasser, J. D., \& Labar, K. S. Neural systems for guilt from actions affecting self versus others. Neuroimage, 2012, 60, 683-92.

[16] Otterbacher, J. R., \& Munz, D. C. State-trait measure of experiential guilt. Journal of Consulting and Clinical Psychology, 1973, 40, 115.

[17] Pardini, D. A., Lochman, J. E., \& Frick, P. J. Callous/unemotional traits and social-cognitive processes in adjudicated youths. J Am Acad Child Adolesc Psychiatry, 2003, 42, 364-371.

[18] Shafran, R., Watkins, E., \& Charman, T. Guilt in obsessivecompulsive disorder. J Anxiety Disord, 1996, 10, 509-516.

[19] Shin, L. M., Dougherty, D. D., Orr, S. P., Pitman, R. K., Lasko, M., Macklin M. L., ..., Ranch, S. L. Activation of anterior paralimbic structures during guilt-related script-driven imagery. Biol Psychiatry, 2000, 48, 43-50.

[20] Smith, R. H., Webster, J. M., Parrott, W. G., \& Eyre, H. L. The role of public exposure in moral and nonmoral shame and guilt. Journal of Personality and Social Psychology, 2002, 83, 138-159.

[21] Takahashi, H., Yahata, N., Koeda, M., Matsuda, T., Asai, K., \& Okubo, Y. Brain activation associated with evaluative processes of guilt and embarrassment: An fmri study. Neuroimage, 2004, 23, $967-$ 74.

[22] Tangney, J. P. Moral affect: the good, the bad, and the ugly. J Pers Soc Psychol, 1991, 61, 598.

[23] Tangney, J. P. Conceptual and methodological issues in the assessment of shame and guilt. Behaviour Research and Therapy, 1996, 34, 741-754.

[24] Tangney, J. P. Self-relevant emotions. In J. P. Tangney \& M. R. Leary (Eds.), Handbook of self and identity (pp. 384-400). New York, NY, US: Guilford Press, 2003.

[25] Tangney, J. P., \& Dearing, R. L. Shame and guilt. New York, NY, US: Guilford Press, 2002.

[26] Tangney, J. P., Dearing, R. L., Wagner, P. E., \& Gramzow, R. H. The Test of Self-Conscious Affect-3 (TOSCA-3). George Mason University, Fairfax, VA, 2000.

[27] Tilghman-Osborne, C., Cole, D. A., \& Felton, J. W.. Definition and measurement of guilt: Implications for clinical research and practice. Clin Psychol Rev, 2010, 30, 536-546.

[28] Tracy, J. L., \& Robins, R. W. Putting the self into self-conscious emotions: A theoretical model. Psychological Inquiry, 2004, 15, 103 125 .

[29] Uphill, M., Groom, R., \& Jones, M. The influence of in-game emotions on basketball performance. Eur J Sport Sci, 2014, 14, 76-83. 
[30] Wagner, U., N'Diaye, K., Ethofer, T., \& Vuilleumier, P. Guiltspecific processing in the prefrontal cortex. Cereb Cortex, 2011, 21, 2461-2470.

[31] Wang, Dan. A functional magnetic resonance imaging research of football players' guilt and compensations. Tongji University, 2017.

[32] Wolf, S. T., Cohen, T. R., Panter, A. T., \& Insko, C. A. Shame proneness and guilt proneness: Toward the further understanding of reactions to public and private transgressions. Self \& Identity, 2010, 9, 337-362.

[33] Yoon, I., \& Yoon, Y. J. Effect of psychological skill training as a psychological intervention for a successful rehabilitation of a professional soccer player: single case study. J Exerc Rehabil, 2014, 10, 295-301.

[34] Yu, H. B., Hu, J., Hu, L., \& Zhou, X. L. The voice of conscience: neural bases of interpersonal guilt and compensation. Soc Cogn Affect Neurosci, 2013, 9, 1150-1158. 